\title{
Incidence of avian flu shocks on poor household livelihoods of poultry farmers in Africa
}

\begin{abstract}
The incidence of Avian influenza (AI) informally known as "bird flu", has been a worldwide cause for concern since the 1960s. Poultry farmers of poor households in developing countries, especially in Sub-Saharan Africa, have received the greatest shocks of the incidence of this disease. The aim of this review is to increase the urgency of understanding bird flu disease. It briefly presents what this zoonotic disease is, gives a brief history of mortality incidents caused by the disease, AI symptoms and control, as well as its incidence on the livelihoods of poor households especially in Sub-Saharan Africa. It is hoped that this review article might increase awareness and argue in support of the great efforts being made by the WHO, FAO, the World Organization for Animal Health and other stakeholders to counteract the devastating adverse consequences of bird flu especially for poor households of SubSaharan Africa.
\end{abstract}

Keywords: avian flu, poultry, household livelihood, Africa, influenza

\author{
Volume 2 Issue I - 2017 \\ Godswill Ntsomboh-Ntsefong, ${ }^{1,2}$ Mohammad \\ Ali Shariati, ${ }^{3}$ Mohammad Usman Khan, ${ }^{4}$ \\ Vesna Karapetkovska-Hristova ${ }^{5}$ \\ 'Institute of Agricultural Research for Development (IRAD), \\ Cameroon \\ ${ }^{2}$ Department of Plant Biologyc, University of Yaounde, \\ Cameroon \\ ${ }^{3}$ Research Department, LLC Science \& Education, Russia \\ ${ }^{4}$ Department of Energy Systems Engineering, University of \\ Agriculture, Faisalabad \\ ${ }^{5}$ Department of biotechnology, Faculty of biotechnical sciences, \\ Macedonia
}

\begin{abstract}
Correspondence: Godswill Ntsomboh Ntsefong, Institute of Agricultural Research for Development, CEREPAH of La Dibamba, P. O. Box 243, Douala, Cameroon, Tel +237 6799419 10,Email ntsomboh@yahoo.fr
\end{abstract}

Received: April 02, 2017 | Published: May 09, 2017

\begin{abstract}
Abbreviations: AI, avian influenza; WHO, world health organization; FAO, food and agricultural organization; SSA, subsaharan african; LPAI, low pathogenic avian influenza; HPAI, highly pathogenic avian influenza; H5N1, haemagglutinin 5 neuraminidase; GISRS, global influenza surveillance response system
\end{abstract}

\section{Introduction}

"Bird flu" or avian influenza (AI) refers to the infectious disease of birds caused by viruses which most commonly infect poultry as well as many types of wild birds. They may also infect a variety of mammals, including humans. AI virus subtypes are distinguished by the haemagglutinin and neuraminidase antigens that cover the virus surface. Each viral subtype is identified by the particular antigen combination it possesses such as $\mathrm{H} 5 \mathrm{~N} 1$ or $\mathrm{H} 3 \mathrm{~N} 2 .{ }^{1}$ AI viruses are classified as low pathogenic (LPAI) or highly pathogenic (HPAI) depending on their virulence. Several African countries have been affected by the H5N1 avian influenza virus in domestic poultry, free-ranging wild birds, captive wild birds and humans. This highly pathogenic $\mathrm{H} 5 \mathrm{~N} 1$ strain has spread from domestic poultry to species of free-ranging wild birds. As of 2007, a list of African countries affected by the H5N1 avian influenza virus in domestic poultry, free-ranging wild birds, captive wild birds and humans since 1996 was presented. ${ }^{1}$ As follows: Burkina Faso, Cameroon, Côte d'Ivoire, Djibouti, Egypt, Ghana, Niger, Nigeria, Sudan and Togo. The virus was first confirmed in 2006 in all these countries except Togo (2007). Outbreaks in these countries were limited almost entirely to poultry apart from three H5N1 AI cases recorded in wild birds: a Sparrow Hawk in Côte d'Ivoire and unspecified duck and vulture species in Cameroon and Nigeria respectively.

Poultry production in most sub-Saharan African (SSA) countries is usually with minimal or no biosecurity measures..$^{2-5}$ Ghana and Nigeria have experienced several outbreaks. ${ }^{6}$ There have been no outbreaks in Kenya and Ethiopia, although both countries have experienced scares resulting in demand shocks (sudden surprise events that temporarily increase or decrease demand for goods or services). Several studies have investigated the impacts of HPAI in SSA. ${ }^{7-12}$ Some of these studies have investigated the impact of HPAI on small-scale producers' livelihoods. ${ }^{13-16}$ The aim of this brief review is to raise awareness and increase urgency of understanding bird flu disease in support of the already existing efforts by major stakeholders and international organizations to prevent and fight against avian influenza outbreaks especially in Africa.

\section{What is bird flu?}

Bird flu or avian influenza (AI) is an infectious disease of birds caused by type A influenza viruses of the Orthomyxoviridae family. In fact, there are three types of influenza viruses: A, B, and C. All those affecting domestic animals like horses, pigs, poultry, etc., belong to type $\mathrm{A}$, (the most common virus type producing serious epidemics in humans). ${ }^{17}$ These viruses most commonly infect poultry as well as many types of wild birds. Some AI viruses are also known to infect a variety of mammals, including humans. AI virus subtypes are distinguished by the haemagglutinin and neuraminidase antigens (glycoproteins) that cover the virus surface. Sixteen different haemagglutinin (H1-H16) and nine different neuraminidase (N1-N9) antigens have been characterized, and each viral subtype is identified by the particular antigen combination it possesses e.g. $\mathrm{H} 5 \mathrm{~N} 1$ or H3N2. All 16 haemagglutinin and nine neuraminidase antigens have been identified in wild bird populations. ${ }^{1}$

A particular AI virus subtype may include a variety of similar but distinct strains based on genetic sequences and the clustering (or not) of the isolates. The different strains originate either through genetic mutation or via recombination or re-assortment of genetic material between different viruses infecting a common host. Specific viral 
strains are identified by several parameters: influenza type; host species from which the strain was isolated; geographic location; laboratory strain designation; year of isolation; and viral subtype. Moreover, AI viruses are classified as low pathogenic (LPAI) or highly pathogenic (HPAI) depending on their virulence in domestic chickens.

\section{Brief historical background on bird flu mortality incidence}

Avian influenza (AI) disease, originally known as Fowl Plague (also known as bird flu) was first recorded in Italy in 1878. Then, several massive outbreaks in poultry were noted, including two outbreaks in the United States (1924 and 1929). By 1955, the virus causing Fowl Plague was discovered to be an influenza virus. An event of AI outbreaks occurred in 1961 during which many Common Terns (Sterna hirundo) were killed by an H5N3 AI in South Africa. In 1997, highly pathogenic avian influenza (HPAI) H5N1 was discovered in humans in Hong Kong. AI has since spread to many countries in Asia, Africa, and the Middle East, infecting hundreds of people and millions of birds some of which died or were culled to prevent further spread of the virus. ${ }^{17} \mathrm{H} 5 \mathrm{~N} 1 \mathrm{HPAI}$ disease outbreak emerged in Asian poultry in 2003/2004. In mid- December 2003, the H5N1 bird flu strain was reported in eight countries across Asia (Cambodia, China, Indonesia, Japan, Lao People's Democratic Republic, Republic of Korea, Thailand and Viet Nam) among bird populations. By February 2004, there were a total of 32 laboratory- confirmed human cases in the region; 22 people died of these cases. This epidemic on populations of domestic and migratory birds triggered fears the virus could mutate into a dangerous human pathogen. ${ }^{18}$

In May 2005, an H5N1 virus mortality event killed over 6,000 water birds at the Qinghai Lake National Nature Reserve in northwest China. About $5-10 \%$ of the entire world's population of Bar-headed Geese was killed during this event. According to, ${ }^{1}$ this was the second documented mortality event of wild birds as the result of an AI virus after the 1961 event in South Africa. Between January and February 2006, the first human cases of H5N1 were detected outside Southeast Asia (Turkey and Iraq). The arrival of the H5N1 HPAI virus in Turkey and Eastern Europe heralded the swift spread of the disease throughout Europe and into the Persian Gulf region by December 2005, and the Middle East and Africa by February/ March 2006. In February 2006, $\mathrm{H} 5 \mathrm{~N} 1$ was detected in commercial poultry in Africa (Nigeria and Egypt), where the virus spread to eight countries by May. Between January and June 2007, H5N1 was detected in poultry in Ghana and Togo in Africa and Kuwait and in captive falcons and poultry in Saudi Arabia in West Asia.

\section{Factors associated with the introduction of Al into a given context}

Several factors are associated with the introduction of HPAIV $\mathrm{H} 5 \mathrm{~N} 1$ into Africa and elsewhere in the world. As reported by, ${ }^{19}$ the following factors determine the introduction of avian flu into a given context:

I. Flyways: Migratory birds constitute a risk for the introduction of HPAIV H5N1 into Africa. The migratory flyways covering areas in Africa represent areas expected to be at higher likelihood of introduction of bird flu ;

II. Surface water, wetlands and waterbodies: These are considered to be aggregation sites for birds and therefore constitute potentially high risk areas for the introduction and transmission of HPAIV. ${ }^{20-26}$

III. Cross-border roads, ports and airports: International poultry trade occurs via these channels and their increasing density is associated with a higher risk of introduction of HPAIV H5N1.22,25,27,28

IV. Poultry density: Increasing density of poultry is associated with a higher contact rate between susceptible and infected birds and therefore greater risk of spread. ${ }^{29-34}$ However, no association was found between poultry density and the risk of HPAIV infection in China, suggesting that this unexpected finding was due to a greater proportion of industrialized chicken production at higher poultry densities, with associated higher biosecurity standards and vaccination protocols.

$V$. Presence of poultry markets or cities : Increasing density of cities are associated with higher demand for poultry products and therefore the presence of trading areas providing live or freshly slaughtered birds. These are consequently high risk zones. ${ }^{34,35-39}$

\section{Avian influenza symptoms}

Avian influenza (AI) infections may produce a mild disease manifested by a variety of respiratory, enteric or reproductive signs (depending on the strain). Clinical signs may include decreases in activity, food consumption or egg production, coughing and sneezing, ruffled feathers, diarrhea and/or tremors. At times, few visible clinical signs are noted and without specific laboratory testing, some LPAI outbreaks may go entirely undetected. Human infections can be acquired through direct contact with infected animals or contaminated environments. Infection of humans by A (H5) or A (H7N9) avian influenza viruses has an aggressive clinical course. Initial symptoms are high fever $\left(\geq 38^{\circ} \mathrm{C}\right)$ and cough. Dyspnoea or difficulty in breathing is also sign and symptom of lower respiratory tract. Sore throat or coryza is a less common symptom of the upper respiratory tract. Other symptoms such as diarrhea, vomiting, abdominal pain, bleeding from the nose or gums, and chest pain have also been reported in some patients. Complications of infection include hypoxemia, multiple organ dysfunction, and secondary bacterial and fungal infections. ${ }^{40,41}$

\section{Avian influenza prevention and control}

In fact, the high impact of avian flu (highly pathogenic avian influenza [HPAI]) require policy makers to consider and put in place appropriate measures for disease surveillance and control systems, especially in developing countries, to control the spread of the disease, notably through the preservation of livelihoods. ${ }^{42}$ A very important step towards prevention is the development of HPAI risk spread map. In fact, an analysis of the spatial distribution of disease risk and its visual presentation through risk maps can help to design targeted and therefore more cost-effective animal disease surveillance strategies. ${ }^{19}$ According to ${ }^{43}$ HPAI shock needs to be treated both as a demand shock due to consumer panic leading to a fall in the price or value of poultry and eggs and a supply shock from disease mortality for poultry. The authors of also recommend that targeted intervention measures should be in place to encourage the adoption of HPAImitigation measures. Households located in risk areas should be given special focus when designing prevention, training and compensation programs. Training and education in biosecurity and better poultry 
production are of paramount importance for disease risk reduction, and are likely to result in high returns.

People at high risk, including poultry farm workers, animal control workers, wildlife biologists, and ornithologists who handle live birds, as well as organizations with high-risk workers should proactively have an avian influenza response plan in place. ${ }^{44}$ Operators should efficiently use personal protective equipment (PPE) especially for the eyes, nose, mouth, and hands; biosafety and biosecurity measures should be implemented with poultry flocks; they should be isolated from outside birds, especially wild birds, and their waste; vehicles used around the flock should be regularly disinfected and not shared between farms. Birds from slaughter channels should not be returned to the farm. Since vaccines for poultry have been formulated against several of the avian H5N1 influenza varieties, control measures for HPAI encourage mass vaccinations of poultry. Quality assured vaccines, when well applied and used in conjunction with other disease control measures, are effective in preventing the introduction of AI viruses and their spread. Evidence suggests that some antiviral drugs, notably oral oseltamivir (Tamiflu) administration, can reduce the duration of viral replication and improve prospects of survival. ${ }^{40,41}$

WHO suggests a 3 phase, 5 part plan for future avian influenza threats. These include: (1) Pre-pandemic Phase (involves reduction of opportunities for human infection, Strengthening of the early warning system); (2) Emergence of a pandemic virus Phase (involves containing or delaying the spread at the source); and (3) the pandemic declared and spreading internationally Phase (involves reduction of morbidity, mortality, and social disruption, and conducting research to guide response measures).

\section{Avian flu incidence on the livelihoods of poor households}

Most poor households depend essentially on subsistence agriculture and livestock. Poultry production is often complementary to crop production; farm manure and cropland area which provide feed and area for scavenging and roaming are inputs to poultry production. ${ }^{45}$ Poultry plays an important role in livelihood outcomes by directly influencing income, wealth, food safety and nutrition security. Households that own other livestock are also more likely to be engaged in poultry, which is considered a first step in the livestock ownership ladder. ${ }^{43,46,47}$ Most rural households have poultry cared for by women, children and vulnerable people (the aged and physically challenged). Family poultry generates $19-50 \%$ of rural family income, makes up about $77 \%$ of the national flock and contributes about $98 \%$ of poultry products consumed in the villages of developing countries. ${ }^{48}$ In sub-Saharan Africa (SSA), women and children tend to be involved in poultry. Women are therefore important stakeholders in village-level poultry in Africa ${ }^{46,49,50}$ where households with lesseducated heads are significantly more likely to keep poultry. This is mainly because household-level poultry is a low-input, low-output activity not requiring high levels of skill and education..$^{2-5,43}$

Despite the important role poultry plays in the livelihood of the poor, lack of diversification in their income and asset portfolios make the poor more vulnerable to shocks such as avian flu especially in the low-income countries of SSA. ${ }^{51,43}$ In fact, with diversified income sources, livelihood outcomes are likely to be resilient against shocks and stresses that may be caused by HPAI outbreaks and scares. ${ }^{52}$ The consequences of AI can be devastating. In Nigeria, for example, poultry prices had not recovered to their pre-shock levels four months after the outbreak. ${ }^{15}$

\section{Conclusion}

The incidence of bird flu on the livelihoods of poultry farmers, especially in poor households in Sub-Saharan African is a real cause for concern. With the regular contact and interaction between poultry and wild birds, it is imperative to continue raising awareness and to increase the urgency of understanding wild bird diseases and the transmission mechanisms that exist between the poultry and wild bird sectors, with a particular emphasis on avian influenza. ${ }^{1}$ Monitoring techniques, mapping, surveillance, habitat use and migration patterns of wildlife and disease ecology are all important aspects to be considered by policy makers and stakeholders. Apart from urgency awareness and control measures, poor householders are encouraged to diversify their income and asset portfolios in order to avert vulnerability to shocks such as avian flu especially in the low-income countries. WHO, in its capacity for providing leadership on global health matters, is monitoring avian and other zoonotic influenza viruses closely through its Global Influenza Surveillance and Response System (GISRS), Specifically, WHO, the World Organization for Animal Health (OIE), and the Food and Agriculture Organization (FAO) collaborate to track and assess the risk from avian and other zoonotic influenza viruses of public health concern. ${ }^{40,41}$ It is to be hoped that this review adds more impetus to all these efforts to counteract the devastating consequences of avian flu, especially for poor households of Sub-Saharan Africa.

\section{Acknowledgements}

The authors are grateful to the anonymous reviewers who proofread and objectively criticized the manuscript, thereby helping us to improve on it.

\section{Conflict of interest}

The author declares no conflict of interest.

\section{References}

1. Whitworth D, Newman SH, Mundkur T, et al. Wild Birds and Avian Influenza: an introduction to applied field research and disease sampling techniques. Rome: FAO Animal Production and Health Manual; 2007.

2. Alemu D, Degefe T, Ferede S, et al. Overview and background paper on Ethiopia's poultry sector: Relevance for HPAI research in Ethiopia. DFID Pro-poor HPAI Risk Reduction Strategies Project Africa/Indonesia Region Report No. 1. USA: International Food Policy Research Institute; 2008.

3. Aning KG, Turkson PK, Asuming-Brempong S. Pro-poor HPAI reduction strategies. Ghana background review paper, Final Report. Prepared on behalf of the Food and Agricultural Organization of the United Nations. UK: Royal Veterinary College; Berkeley: University of California; USA: International Food Policy Research Institute; and International Livestock Research Institute; 2008.

4. Obi U, Oparinde AO, Maina GA. Pro-poor HPAI risk reduction strategies: Nigeria background paper. Nigeria: International Livestock Research Institute and International Food Policy Research Institute; 2008.

5. Omiti JO, Okuthe SO. An overview of the poultry sector and status of highly pathogenic avian influenza (HPAI) in Kenya - Background paper. Collaborative Research on Pro-poor HPAI Risk Reduction, Africa/ Indonesia Team Working Paper No. 4. USA: International Food Policy Research Institute (IFPRI); 2008.

6. Henning J, Bett B, Okike I, et al. Incidence of highly pathogenic avian influenza H5N1 in Nigeria, 2005-2008. Transbound Emerg Dis. 2013;60(3):222-230. 
7. You L, Diao X. Assessing potential impact of avian influenza on poultry in West Africa: A spatial equilibrium model analysis. Journal of Agricultural Economics. 2007;58(2):348-367.

8. Diao X. Economywide impact of avian flu in Ghana: A dynamic CGE model analysis. USA: International Food Policy Research Institute; 2009.

9. Diao X, Alpuerto V, Nwafor M. Economy wide impact of avian flu in Nigeria-a dynamic CGE model analysis. DFID-funded Project for Controlling Avian Flu and Protecting People's Livelihoods in Africal Indonesia. HPAI Research Brief 15. USA: International Food Policy Research Institute/International Livestock Research Institute (ILRI)/ Royal Veterinary College (RVC); 2009.

10. Schmitz C, Roy D. Potential impact of HPAI on Ghana: A multimarket model analysis. DFID-funded Project for Controlling Avian Flu and Protecting People's Livelihoods in Africa/Indonesia. HPAI Research Brief 14. USA: International Food Policy Research Institute/ International Livestock Research Institute (ILRI)/Royal Veterinary College (RVC); 2009.

11. Thomas M, Diao X, Roy D. Impact of a potential avian flu outbreak in Ethiopia: A multimarket model analysis. DFID-funded Project for Controlling Avian Flu and Protecting People's Livelihoods in Africal Indonesia. HPAI Research Brief 13. USA: International Food Policy Research Institute/International Livestock Research Institute (ILRI)/ Royal Veterinary College (RVC); 2009

12. Thurlow J. Implications of avian flu for economic development in Kenya. Discussion Paper 951. USA: International Food Policy Research Institute; 2010.

13. Bush J. The threat of avian flu. Predicted impacts on rural livelihoods in Southern Nation, Nationalities and Peoples Region (SNNPR), Ethiopia. Pittsburgh: The Food Economy Group; 2006.

14. Kimani T, Obwayo M, Muthui L. Avian flu threat: Socio-economic assessment of the impacts on poultry-related livelihoods in selected districts in Kenya. Kenya: Pan-African Program for the Control of Epizootics (PACE); 2006.

15. UNDP (United Nations Development Program). Socio $\square$ economic impact of avian influenza in Nigeria. Abuja, Nigeria; 2006.

16. Obayelu AE. Socio-economic analysis of the impacts of avian influenza epidemic on households poultry consumption and poultry industry in Nigeria: empirical investigation of Kwara State. Livestock Research for Rural Development. 2007:19(4).

17. World Health Organization (WHO). Avian flu virus could evolve into dangerous human pathogen, experts fear. Bulletin of the World Health Organization. WHO News, Geneva; 2004. 82(3):236-237.

18. Stevens KB, Costard S, Métras R, et al. Mapping the Likelihood of Introduction and Spread of Highly Pathogenic Avian Influenza Virus $\mathrm{H} 5 \mathrm{~N} 1$ in Africa, Ghana, Ethiopia, Kenya and Nigeria using Multicriteria Decision Modelling. DFID Africa-Likelihood maps. UK: Royal Veterinary College; 2009.

19. Hlinak A, Mühle RU, Werner O, et al. A virological survey in migrating waders and other waterfowl in one of the most important resting sites of Germany. J Vet Med B Infect Dis Vet Public Health. 2006;53(3):105-110.

20. Jourdain E, Gauthier-Clerc M, Bicout DJ, et al. Bird migration routes and risk for pathogen dispersion into western Mediterranean wetlands. Emerg Infect Dis. 2007;13(3):365-372.

21. Ducatez MF. Multiple introductions of H5N1 in Nigeria - Phylogenetic analysis reveals thatthis deadly virus first arrived in Africa from different sources. Nature. 2006;442(7098):37-37.

22. Gaidet N, Dodman T, Caron A, et al. Avian influenza viruses in water birds, Africa. Emerg Infect Dis. 2007;13(4):626-629.
23. Gaidet N, Cattoli G, Hammoumi S, et al. Evidence of infection by H5N2 highly pathogenic avian influenza viruses in healthy wild waterfowl. PLoS Pathog. 2008;4(8):e1000127.

24. Martinez M, Munoz MJ, De La Torre A, et al. Risk of Introduction of H5N1 HPAI from Europe to Spain by Wild Water Birds in Autumn. Transbound Emerg Dis. 2009;56(3):86-98.

25. Kilpatrick AM, Chmura AA, Gibbons DW, et al. Predicting the global spread of H5N1 avian influenza. Proc Natl Acad Sci U S A. 2006;103(51):19368-19373.

26. Vannier P. Avian influenza; routes of transmission: lessons and thoughts drawn out of the past and present situation in the world and in the European Union. PathologieBiologie. 2007;55(6):273-276.

27. Fang LQ, de Vlas SJ, Liang S, et al. Environmental factors contributing to the spread of H5N1 avian influenza in mainland China. PLOS ONE. 2008;3(5):e2268.

28. Cecchi G, Ilemobade A, Le Brun Y, et al. Agro-ecological features of the introduction and spread of the highly pathogenic avian influenza (HPAI) H5N1 in northern Nigeria. Geospat Health. 2008;3(1):7-16.

29. Mannelli A, Ferre N, Marangon S. Analysis of the 1999-2000 highly pathogenic avian influenza $(\mathrm{H} 7 \mathrm{~N} 1)$ epidemic in the main poultryproduction area in northern Italy. Prev Vet Med. 2006;73(4):273-285.

30. Gilbert M, Chaitaweesub P, Parakamawongsa T, et al. Free-grazing ducks and highly pathogenic avian influenza, Thailand. Emerg Infect Dis. 2006;12(2):227-234.

31. Nishiguchi A, Kobayashi S, Yamamoto T, et al. Risk factors for the introduction of avian influenza virus into commercial layer chicken farms during the outbreaks caused by a low-pathogenic H5N2 virus in Japan in 2005. Zoonoses Public Health. 2007;54(9-10):337-343.

32. Tiensin T, Chaitaweesub P, Songserm T, et al. Highly pathogenic avian influenza H5N1, Thailand, 2004. Emerg Infect Dis. 2005;11(11):1664 1672 .

33. Kung NY, Morris RS, Perkins NR, et al. Risk for infection with highly pathogenic influenza A virus (H5N1) in chickens, Hong Kong, 2002. Emerg Infect Dis. 2007;13(3):412-418.

34. Bulaga LL, Garber L, Senne DA, et al. Epidemiologic and surveillance studies on avian influenza in live-bird markets in New York and New Jersey, 2001. Avian dis. 2003;47(3):996-1001.

35. Cheung CL, Vijaykrishna D, Smith GJ, et al. Establishment of influenza A virus (H6N1) in minor poultry species in southern China. Journal of virology. 2007;81(91):10402-10412.

36. Choi YK, Seo SH, Kim JA, et al. Avian influenza viruses in Korean live poultry markets and their pathogenic potential. Virology. 2005;332(2):529-537.

37. Nguyen DC, Uyeki TM, Jadhao S, et al. Isolation and characterization of avian influenza viruses, including highly pathogenic H5N1, from poultry in live bird markets in Hanoi, Vietnam, in 2001. J Virol. 2005;79(7):4201-4212.

38. Pfeiffer DU, Minh PQ, Martin V, et al. An analysis of the spatial and temporal patterns of highly pathogenic avian influenza occurrence in Vietnam using national surveillance data. Vet J. 2007;174(2):302-309.

39. American Public Health Association (APHA). Control of Communicable Diseases Manual 20th Edition. USA: APHA Press; 2015.

40. World Health Organization (WHO). Avian and other zoonotic influenza. Fact sheet Updated November 2016. Media centre. 2017.

41. Sonaiya EB, Branckaert RDS, Guèye EF. Research and development options for family poultry. First INFPD/FAO Electronic Conference; 1999. 
42. Birol E, Asare-Marfo D, Ayele G, et al. The impact of avian flu on livelihood outcomes in Africa: evidence from Ethiopia, Ghana, Kenya and Nigeria. African Journal of Agricultural and Resource Economics. 2013;8(4):275-288.

43. Wikipedia. Avian influenza. 2017.

44. Wadsworth JJ. An analysis of major farm characteristics and farmers' use of cooperatives. Journal of Agricultural Cooperation. 1991;6:45-53.

45. Gueye EF. The role of family poultry in poverty alleviation, food security and the promotion of gender equality in rural Africa. Outlook on Agriculture. 2000;29:129-136.

46. Aklilu HA, Udo HMJ, Almekinders CJM, et al. How resource poor households value and access poultry: Village poultry keeping in Tigray, Ethiopia. Agricultural Systems. 2008;96:175-183.

47. Sonaiya EB. Family poultry, food security and the impact of HPAI. World's Poultry Science Journal. 2007;63(1):132-138.
48. Alders RG. Facilitating women's participation in village poultry projects: Experiences in Mozambique and Zambia. Proceedings of the 20th World Poultry Congress. 1996;3:441-447.

49. Gueye EF. Poultry plays an important role in African village life. World Poultry Science Journal. 1998;14(10):14-17.

50. Livestock in Development. Livestock in poverty-focused development. Crewkerne: Livestock in Development; 1999.

51. Ellis F. Rural livelihoods and diversity in developing countries. Oxford: Oxford University Press; 2000.

52. OIE. OIE Situation Report for Avian Influenza. Current Global Situation: World Organisation for Animal Health: protecting animals, preserving our future. 2017. 